\title{
OUTCOME OF SURGICAL TREATMENT IN CASES OF DISSOCIATED VERTICAL DEVIATION NOT ASSOCIATED WITH OBLIQUE MUSCLES DYSFUNCTION
}

\author{
El-Khattabi, M., Kasem, M. ${ }^{(*)}$, Abd El-Hamid, A., Nafie, E. \& Mokbel, Th. \\ Ophthalmology dept., Faculty of Medicine, Mansoura Univ., Mansoura, Egypt \\ ${ }^{(*)}$ E-mail: manal_kas2006@yahoo.com
}

\begin{abstract}
Purpose: To evaluate the outcome of three surgical interventions: Bilateral superior rectus (SR) recession, bilateral $S R$ Faden surgery, bilateral $S R$ recession with Faden surgery in management of dissociated vertical deviation (DVD) not associated with oblique muscles dysfunction. Patients and Methods: This study includes 30 patients with comitant dissociated vertical deviation, they attended Mansoura Ophthalmic center for surgical management of their ocular deviation. They were divided into 3 groups according to procedure of the management. 10 patients were operated by bilateral superior rectus recession with Faden procedure (BSRRf), 10 patients operated by bilateral superior rectus recession only (BSRR), and 10 patients were operated by bilateral superior rectus Faden procedure only (BSRF). The results were compared. The patients were followed for 6 months postoperative. Results: Orthotropia were obtained in 9 cases of (BSRRf) group, while it was obtained only in 4 cases of (BSRR) and 2 cases of (BSRf) became orthotropic. Conclusion: Bilateral superior rectus recession with Faden (BSRRf) is more effective than bilateral superior rectus recession (BSRR) and bilateral Faden (BSRF) in cases of DVD.
\end{abstract}

Keywords: Dissociated vertical deviation, superior rectus recession, Faden procedure, comitant DVD

\section{Introduction}

Dissociated vertical deviation (DVD) is a vertical ocular deviation occurs when binocularity is suspended. It is characterized by abduction, elevation and excyclotortion of the un fixating eye without contralateral hypotropia; it represents a challenge for diagnosis and surgical treatment [1,2]. DVD is usually asymmetrical, bilateral; the degree of symmetry is determined by the magnitude of the deviation of both eyes in primary position. Comitant DVD is said to be present when the vertical deviation (within $+/-7 \mathrm{pd}$ ) measures same in abduction, primary position and adduction. When planning for surgery, the degree of asymmetry and comitancy are important factors $[3,4]$. DVD may be isolated or may a part of other types of strabismus. DVD is commonly associated with intermittent exotropia, and infantile esotropia [5-7]. Surgery for DVD is indicated if DVD is large, and represents a cosmetic problem. Standard surgery is bilateral superior recession. Posterior fixation 
(faden) suture is recently used as another line of treatment, the aim of the faden is to shift the effective insertion of the superior rectus muscle posteriorly. Theoretically this may reduce the effectiveness of that muscle in its field of action $[2,8]$. The aim of the work is to

\section{Patients and Methods}

The study was a comparative randomized study prospective study, and carried out on 30 patients of bilateral DVD without oblique muscle dysfunction, who attended the Outpatient strabismus clinic of Mansoura University Ophthalmic center during the period from July 2016 to June 2017. A written consent was obtained from all patients or their parents before enrollment in the study and after an explanation was provided of the procedure to be performed and the possible outcomes. They were also informed about the need for repeated follow-up visits. The study was approved by IRB (Institutional Reviewer Board) of Mansoura faculty of Medicine Mansoura University of code number: MD/16.06.01. Cases of DVD with oblique muscles dysfunction were excl- evaluate the outcome of three surgical interventions: bilateral superior rectus (BSRR) recession, bilateral superior rectus (BSRf) Faden surgery bilateral SR recession with Faden surgery (BSRRf) in management of DVD (not associated with oblique muscles dysfunction).

uded. All patients were examined in the strabismus clinic for assessment of visual acuity (uncorrected and best corrected visual acuity), cycloplegic refraction, anterior segment, and posterior segment examinations. Ocular motility assessment was done including both ductions and versions. The angle of deviation was measured for both distance and near, with and without spectcles. The measurement of the angle was done by alternate prism and cover test in the primary position. Sensory status was assessed by TNO, and Worth 4 dots test. Our study groups were divided equally and randomly into 3 groups according to the surgical approach used for the treatment of DVD. All surgeries were performed by the same surgeon (second author).

\section{Surgical Procedures}

\subsection{Bilateral superior rectus recession}

Patients in group I underwent large bilateral superior rectus recession only. The superior rectus was recessed using a double-armed 6-0 vicryl suture. Recession of the superior rectus for the desired number of $\mathrm{mm}$ from the insertion site. The intermuscular attachments were cut on both sides of the muscle, with good posterior dissection and isolation of the

\subsection{Bilateral superior rectus recession combined with posterior fixation sutures (Faden procedure)}

Group II underwent bilateral superior rectus recession combined with posterior fixation sutures (Faden procedure). In this technique, the superior rectus was recessed with Faden procedure which requires extreme posterior exposure. Faden

\subsection{Faden procedure}

Group III underwent bilateral superior rectus Faden surgery alone. The technique muscle. Special care must be taken to avoid injury of the superior oblique insertion. Also with large recessions of the superior rectus muscle to avoid postoperative retraction of the upper eye lid, so must be taken to dissect between superior rectus and levator palpebrae superioris muscle

is placed through the sclera $14 \mathrm{~mm}$ posterior to the original muscle insertion. A non-absorbable 5-0 Polyester suture with spatulated needle was used.

was performed as group 2 but without superior rectus recession. Postoperatively, 
the patients were examined regularly in our outpatient strabismus clinic as the same preoperative manner by the same investigator to assess the surgical outcome, evaluation of both vertical and horizontal alignment, and detection of any residual

\section{Results}

Thirty patients who came for surgical correction of DVD were divided into 3 groups: group1, included 10 patients, they were undergo of bilateral superior rectus recession (BSRR). Group 2, included 10 patients, they were undergo of Bilateral Superior Rectus Recession combined with posterior fixation suture (BSRRf). Group 3 included 10 patients, they were undergo of Bilateral Superior Rectus posterior fixation suture (Faden procedure) (BSRf) without recession. Table (1) shows the demographic data of the patients. We considered the success value is orthotropia within 8 prism diopters as a success value. The postoperative results showed that 9 patients became orthotropic after BSRRf
DVD. The data were reported at 1 week, 1 month, 3 month, and 6months after surgery. Data was collected, tabulated and analyzed using SPSS (version 16). $P$ values less than 0.05 was considered statically significant.

(group 2), and only one patient had residual DVD. While 4 patients became orthotropic in group 1 (BSRR), and 6 patients had residual DVD. Only 2 cases became orthotropic in group 3 . The results are shown in table (2). There was a highly significant $\mathrm{p}$ value between group 2 (BSRRf), and both group 1 (BSRR) and 3 (BSRf) regarding postoperative number of patients with orthotropia, and residual angle. Figure (1) shows a case of group 1 (BSRR), with late residual DVD at end of 6 months. Figure (2) shows a case of group 2(BSRRF), with orthotropia at end of 6 months. Figure (3) shows a case of group 3 (BSRf), with late large residual DVD at end of 6 months.

Table (1) Demographic data of the patients

\begin{tabular}{|l|c|c|c|}
\hline No & $\begin{array}{c}\text { Group 1 } \\
\text { (BSRR)* }\end{array}$ & $\begin{array}{c}\text { Group 2 } \\
\text { (BSRRf)*** }\end{array}$ & $\begin{array}{c}\text { Group 3 } \\
\text { (BSRf)**** }\end{array}$ \\
\hline Age (years) & 10 & 10 & $\mathbf{1 0}$ \\
\hline Sex (male/ females) & $6-18$ & $7-22$ & $\mathbf{6 - 1 5}$ \\
\hline Pre - operative angle (pd)**** & $6 / 4$ & $5 / 5$ & $\mathbf{7 / 3}$ \\
Mean \pm sd & $10-20$ & $10-26$ & $\mathbf{1 0 - 1 8}$ \\
\hline Superior rectus recession (mm) & $15 \pm 3.0$ & $16 \pm 4$ & $\mathbf{1 2} \pm \mathbf{2 . 0}$ \\
Mean \pm sd & $\mathbf{6 - 9}$ & $\mathbf{7 - 1 0}$ & - \\
\hline
\end{tabular}

* BSRR: Bilateral superior rectus recession, $* *$ BSRRf: Bilateral Superior rectus recession combined with faden procedure, $* * * \mathbf{B S R f}$ : Bilateral Superior rectus faden procedure, $* * * *$ pd: prism diopter.

Table (2) Postoperative results

\begin{tabular}{|l|c|c|c|c|}
\hline & $\begin{array}{c}\text { Group 1 } \\
\text { (BSRR)* }\end{array}$ & $\begin{array}{c}\text { Group 2 } \\
\text { (BSRRf)*** }\end{array}$ & $\begin{array}{c}\text { Group 3 } \\
\text { (BSRf)**** }\end{array}$ & P \\
\hline Orthotropia & $4(40 \%)$ & $9(90 \%)$ & $2(20 \%)$ & $\mathbf{0 . 0 0 1}$ \\
\hline Residual DVD**** & $6(60 \%)$ & $1(10 \%)$ & $8(80 \%)$ & $\mathbf{0 . 0 1}$ \\
\hline Residual angle (pd)***** & $\mathbf{1 0} \pm \mathbf{5}$ & $\mathbf{4} \pm \mathbf{2}$ & $\mathbf{1 2} \pm \mathbf{3 . 0}$ & $\mathbf{0 . 0 1}$ \\
\hline
\end{tabular}

* BSRR: bilateral superior rectus recession, ** BSRRf: Bilateral Superior rectus recession combined, with faden procedure, $* * *$ BSRf: Bilateral Superior rectus faden procedure, $* * * *$ DVD: Dissociated vertical deviatioin, $* * * * *$ pd: prism diopter. 

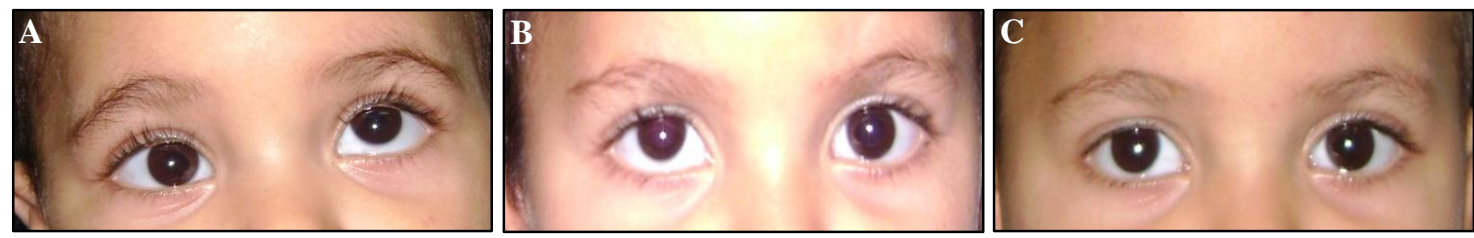

Figure (1) $\underline{\mathbf{A}} \& \underline{\mathbf{B}}$; bilateral DVD, $\underline{\mathbf{C}} ; 6$ months postoperative (After bilateral superior rectus recession $9 \mathrm{~mm}$ of group 1) with residual small angle in Rt. eye.
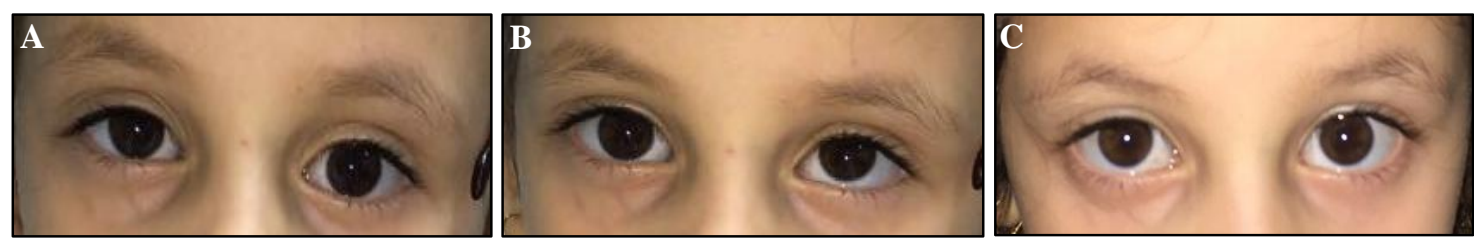

Figure (2) $\underline{\mathbf{A}} \& \underline{\mathbf{B}}$; bilateral DVD. $\underline{\mathbf{C}}$; 6 months postoperative (After bilateral superior rectus recession $6,8 \mathrm{~mm}$ with faden procedure of group 2 ), with no residual angle.
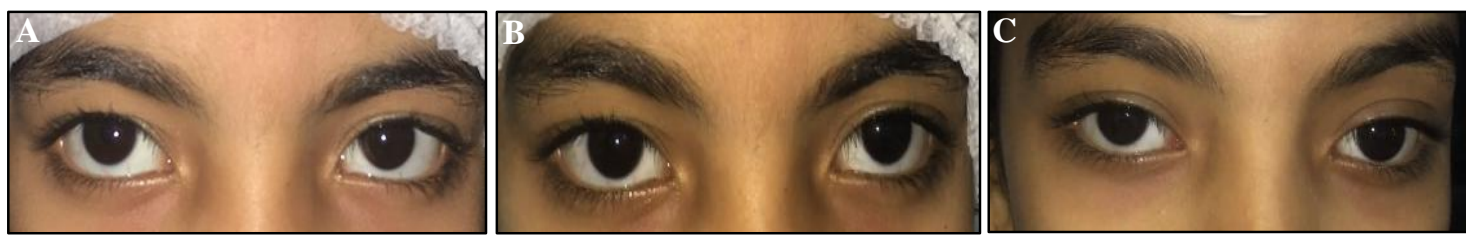

Figure (3) $\underline{\mathbf{A}} \& \underline{\mathbf{B}}$; bilateral DVD. $\underline{\mathbf{C}} ; 6$ months postoperative (After bilateral superior rectus faden procedure of group 3, with large residual angle.

\section{Discussion}

Dissociated strabismus characterized by an up drift, exotropia, and extortion of the unfixing eye. Vertical up drift is the main component of dissociated vertical deviation (DVD) [4]. Surgical management of DVD is indicated if significant hypertropia is manifested spontaneously, or those associated with horizontal misalignment. Surgical treatment is aimed to obtaining a latent vertical deviation, with less amount [9]. As DVD is a bilateral, asymmetrical. The degree of asymmetry is variable; it may be slight, moderate or large. A study by Magoon, Cruciger and Jampolsky found an average asymmetry of 10.3 prism diopters. Surgery only indicated for cosmetic purpose [10]. The non-surgical treatment modalities may also use as orthoptics, and prisms. Alone or in combination with surgical methods [11]. In our study the decision whether to perform combined SRR with Faden procedure, or sole, or Faden only. It was found that in treating DVD the elevating forces of the eye must either be crippled or the eye tethered in down gaze, since the superior rectus is the greatest elevator, it makes sense that

weakening of this muscle is the target [12]. Guillermo Velez [10] mentioned that the traditional recession of superior rectus less than $5 \mathrm{~mm}$ is ineffective for treatment of DVD, so we did not perform recession lesser than $6 \mathrm{~mm}$. Jampolsky [11] mentioned that large superior rectus recession of 9-16 mm bilaterally is the treatment of choice. In our study the maximum sole superior rectus recession was $9 \mathrm{~mm}$ and 4 cases were orthotropic and 6 cases had a residual deviation. It was reported that sometimes patients developed a larger angle in the eye that had DVD than before surgery after performing sole posterior fixation suture (Faden procedure) [13,14]. This is in agreement of our study which we found the same finding with cases in the third group with the sole superior rectus Faden surgery. Brain Harcourt, confirmed this by stating that The posterior fixation suture of superior rectus is different from that of other rectus muscle weakening operations, as the dissociated eye drifts upwards there is progressive weakening of this muscle by the surgery. These immediate effects are usually encouraging, but later on the recurrence is common. 
So the doubts still remain about the long term durability of the initially satisfactory results [15]. In our study we did a large SR recession 7-9 $\mathrm{mm}$ together with retroequatorial myopexy (14-16 mm of original insertion) and the result was satisfactory even more than accompanying the Faden suture with small SR recession and there was no complication or postope- rativehypotropia. Esswein et al [16] achieved good results with 7-9 mm recessions with posterior fixation sutures compared with sole superior rectus muscle recessions in 228 patients with DVD, in agreement with our results in group 2of combined SRR and Faden procedure.

\section{Conclusion}

Superior rectus recession combined with posterior fixation sutures for the primary treatment of DVD without oblique muscle dysfunction is more effective than superior rectus recession alone, or superior rectus Faden surgery.

\section{References}

1. Uncovska, E., Vancurova, J., Anterior transposition versus myectomy of the inferior oblique muscle in the treatment of DVD. Scripta Medica 2003; 76 (2): 111-118.

2. Guyton, D., Dissociated vertical deviation: Etiology, mechanism, and associated phenomena. JAAPOS 2000; 4 (3):131-144.

3. Saxena, R., Sinha, A., Menon, V. \& Turaka, K., Dissociated vertical deviation. DOS Times 2006; 12 (3): 201203.

4. Velez, F., Ela-Dalman, N., Velez, G., Surgical management of dissociated vertical deviation associated with apattern strabismus. JAAPOS 2009; 13 (1): 31-35.

5. Clarke, W., Noel, L., Surgical results in intermittent exotropia. Can J Ophthalmo 1981; 16 (2): 66-69.

6. von Noorden, G., Campos, E., Binocular vision and ocular motility. In: $\boldsymbol{6}^{\text {th }} \boldsymbol{e d}$. St. Louis (MO): Mosby; 2002. pp. 378385.

7. Velez, G., Dissociated vertical deviation. Graefes Arch Clin Ophthalmol 1988; 226 (2):117-118.

8. Von Noorden, G., The posterior fixation suture in strabismus surgery. In: Symp. on Strabismus. Transactions of the New Orleans Academy of Ophthalmology. St Louis: CV Mosby; 1978. p. 578.
9. Harcourt, B., Mein, J., Johnson, F., Natural history and associations of dissociated vertical divergence. Trans. Ophtahlmol Soc 1980; 100: 495-497

10. Loba, P., Loba, A., Difficulties in diagnosis and treatment of dissociated vertical deviation (DVD), Part I. Klin Oczna 2007; 109 (7-9): 356-358.

11. Helveston, E., Dissociated vertical deviation a clinical and laboratory study. Trans Am Ophthalmol Soc 1980; 78: 734-779.

12. Eustis, H., Surgery for dissociated vertical deviation: for superior rectus recession. American Orthoptic J. 1998; 48: 30-33.

13. Can, D., Ozkan, S., Kasim, R., Duman, S., Surgical results in highly a symmetric dissociated vertical deviations. Strabismus, 1997; 5: 21-26.

14. Sprague, J., Moore, S., Eggers, H., Knapp, P., Dissociated vertical deviation treatment with the faden operation of Cüppers. Arch Ophthalmol, 1980; 98: 465-468.

15. Harcourt B., Faden operation (posterior fixation suture). Eye 1988; 2: 36-40.

16. Esswein, M., von Noorden G, Coburn, A., Comparison of surgical methods in the treatment of dissociated vertical deviation. Am J Ophthalmol 1992; 113: 287-290 